\title{
Understanding to Enhance, Between the Technical and Humanist Approaches
}

Elena Ippoliti

\section{Abstract}

The topics brought to attention by the Symposium provide the opportunity to reflect on research experiences in the last fifteen years where the potential of digital technology, and augmented reality in particular, has been tested to enhance the cultural heritage. It is an opportunity to verify - beyond not only the apparent kaleidoscope of the latest technological "novelty or wonder", applications, and goals, but also changing groups of scholars or case studies - the presence or lack of a driving motive with regard to both the general goals and the specific discipline of Disegno, thereby validating, again at a distance of several years, the different experiences.

Keywords

representation and communication of cultural heritage, representation of the city, communication and visual perception, gamification, storytelling.

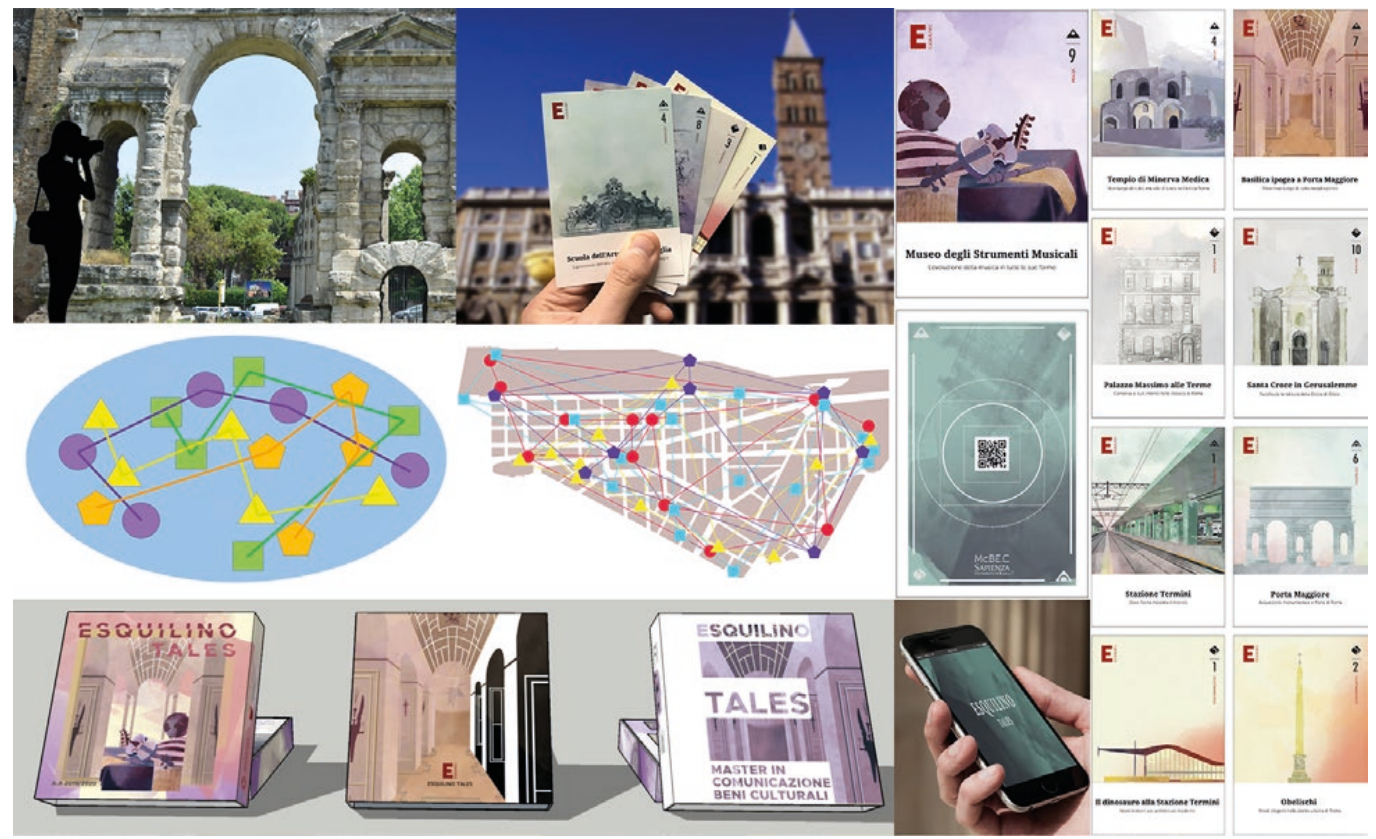


Fig. I. The figure wants to summarize the common purpose of a set of researches: publishing and sharing bodies f knowledge about the cultural heritage manized through the real, geographical, the real, geographical, and web spaces. From Maps, technological and spatial models for understanding, promotion and sharing urban heritage, PRIN 2007-2009" and Towards the construction of a Digital Atlas for the documentation of cloisters and courtyards in Ascoli Piceno, 2006-2008.

\section{The Model}

The starting point of the reflection lies in research [I] that has selected critical reflection and experimental investigation of digital technologies as a favoured area to enhance the cultural heritage by defining "visual models for knowledge and use" [2].

The first approach was mostly aimed at faithful, imitative modelling of reality, with a focus on solving problems related to the details of reconstruction - number of polygons, rendering quality, textures, lighting, etc. This setting conditioned the possibilities for online exploration, preventing correspondence with the goals of the research, i.e. publishing and sharing bodies of knowledge about the cultural heritage organized through 3D models integrated with the real, geographical, and web spaces.

Technological developments (from miniaturization of the components to identification of algorithms for data compression) already allowed for some hybrids between real and virtual, variously refined by the subject's level of interaction with the real space, presence, and type of device. In particular, the first applications of augmented reality - or more properly mixed reality - had already been developed for smartphones (having just been equipped with GPS, electronic compass and inclinometer, camera, and wireless connection), although severely limited in their integration between real/natural and virtual vision, frequency with which the virtual scene was updated, adherence of this to the real space, etc.

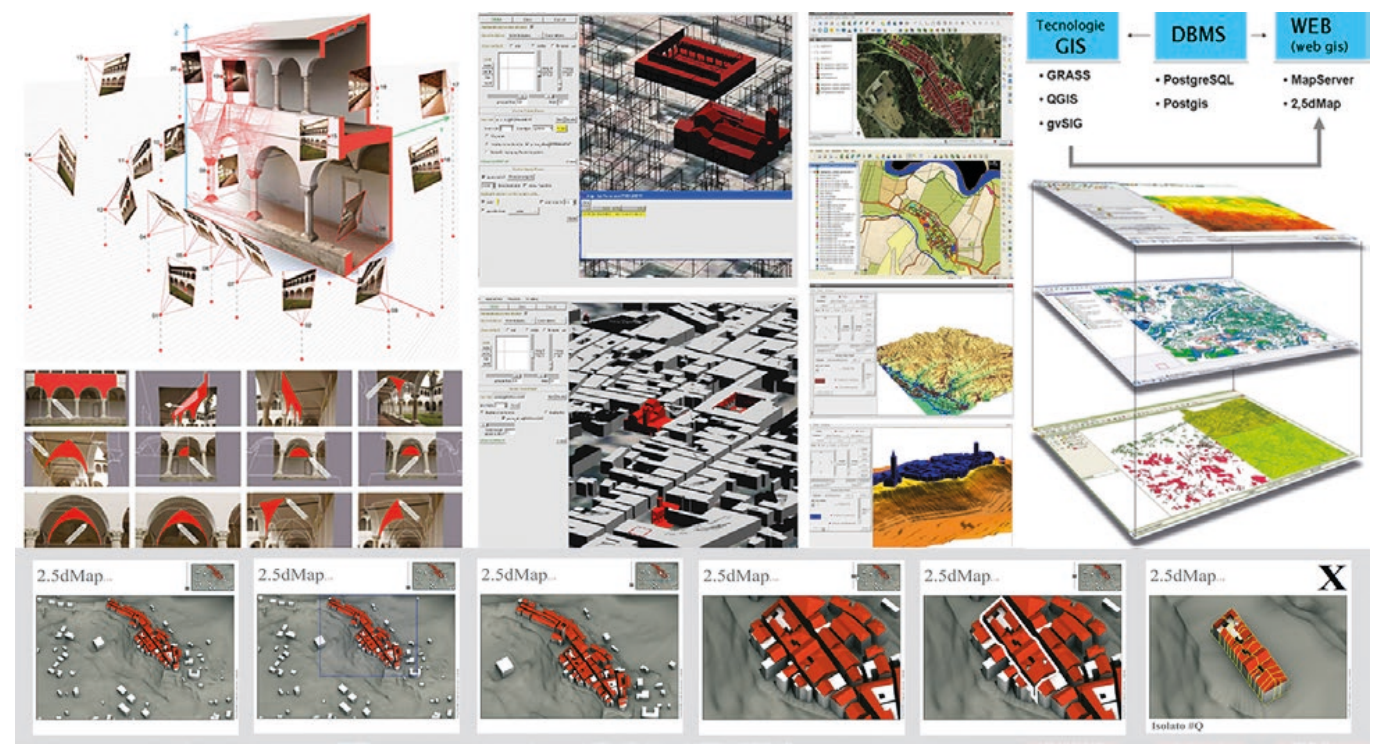

Nevertheless, pursuing the objectives of the research and relying on technical/procedural expedients to overcome the technological limits, we explored the entire arc of the real-virtual continuum, trying to variously combine the different terms in play (real, virtual, devices, etc.) to probe the different perceptual responses.

In some way, we practised the three-dimensional taxonomy developed by Milgram and others [Milgram et al. 1994; Milgram et al. 1995] on AR applications obtained from the entire mixed reality spectrum. In this taxonomy, two dimensions (reproduction fidelity and extent of presence metaphor) are closely related because the question of realism (or better yet, plausibility) of the scene is related to the measure with which subjects perceive their participation in the scene - from either outside or inside. The third dimension (extent of world knowledge) instead measures the subject's judgement of the integration of the virtual content with the real world. This, however, is not only a function of the viewer's exact position in the scene, but also where the intelligence of human perception intervenes to "close the cycle" [Milgram et al. 1995, p. 287].

In this framework, the "visual models of knowledge and use" were modified - from the "3D digital representation/model" to the "informed 3D model" to the "digital 3D scene" [Ippoliti, Meschini 2010] - with an ontological shift in the representation/vision from 'objective' to 
Fig. 2. AR experiences about Piazza Arringo Ascoli Piceno. From Informative integrated Models to know, improve and share urban and environmental heritage. Testing 3D interfaces for cultural and geographic objects': the architecture of the information and computerized architecture", PRIN 2009-2012" 'subjective', turning the observer into a spectator and then an actor, no longer in front of the representation but within the scene.

The 'digital 3D scene' became a participatory place by virtue of which one could effectively realize the construction, access to, and sharing of cultural content. Different types of 'visual 3D models' have been explored in this view for a similar number of applications and tours relying on augmented reality and virtual reality according to different degrees of interaction and/or immersion.

\section{The Topic}

In this framework, we tested different applications of AR (or, as mentioned above, MR) on very different case studies (a neighbourhood, square, set of goods with uniform characteristics, etc., but also a collection of representations of an urban space, square, etc.), all of which, however, were types of cultural goods that transmit their value starting from their state as a 'figure'. These goods should be used consistently with their specific signs in visual languages that encourage modes of exploration, thus consistent with the goals of the experimentation: interpreting the simulation of the space and the set of visual technologies for accessible, participatory, and involving communication of the heritage. The "3D scene" is therefore the key to access the cultural heritage because the emotional emphasis tied to vision activates involvement, encouraging participation and turning the cultural good into an experience.

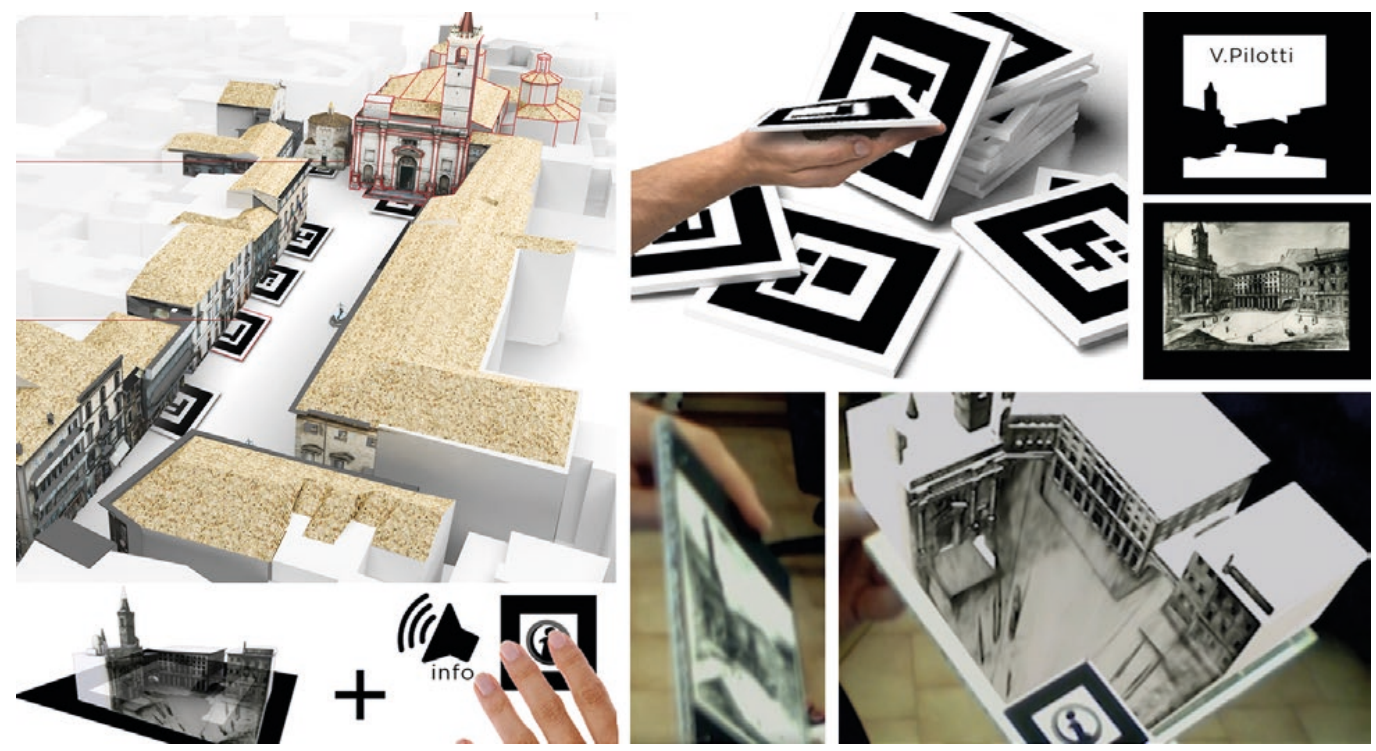

The case studies, however, are always anchored to the authentic motive for the research, which originates in defining the cultural good itself as the expression of the system, that is, the set of qualitative and quantitative connections between the individual goods and between these and the context. This is a fundamental awareness for Italy leading to the culture of enhancement, "in which the value of each individual monument or object of art results not from its isolation, but from its insertion in a vital context" [Settis 2002, p. 15]. The process of building knowledge therefore cannot be limited to the good in itself, but should express its interactions - both physical and linguistic - with the context where it originated, making the fabric of relationships that give it substance and clarify it explicit and tangible. It is in this context that we should begin to explore and learn about the "evidence with civic value".

\section{The Map}

Indispensable in this revisitation is another body of research focused on 'maps' [3], a logical paradigm and technically concrete place in which information is always contextual. Each datum is associated with a specific location in the map space, and it is this space itself that allows the nodes between data and positions to be highlighted. Maps are an organized form of anthropic 
Fig. 3. AR experiences about the Archaeological Museum, Palazzo Panichi, Piazza Arringo, Ascoli Piceno. From top to bottom: AR mobile device: simulations of a virtual reconstruction of the ionic column; AR desktop application: the sepulchral Epigraph of the concubine Pontia Callista. From Informative integrated Models to know, improve and share urbon and environmental uran an 3 interfoces for cultura and 'cultural and geographic 'ojects: the architecture of the information and computerized architecture PRIN 2009-20I2" space that enable the complexity of reality to be penetrated through reduction into a model, but it is above all a means in which the individual parts and whole are understood through relationships, the only thing that can define the contextual meaning of the phenomenon.

These reflections led us first to experiment with the different means through which a map/ representation communicates: icons, through similarity with the object, in which the information/communicational flow is continuous; and language, through signs and symbols, in which the flow is discontinuous.

These then led us to test different enunciative means of cartographic 'discourse': description and narration [Marin 200 I]. In description, the gaze is panoptic and simultaneously embraces multiple points of view, expressing an atemporal spatiality. In narration, in contrast, the view is that of a traveller crossing spaces and itineraries and the points along the path follow a spatiality, expressing the temporal dimension.

The sense of the AR and MR experiences falls within these reflections. They are methods and devices to create visual models designed as interfaces to share content between the transmitter and subjects, for whom viewing becomes an experience, encouraged as they are to participate in the message of communication. The range of infographic methods only acquires a sense when viewed in light of the application of contextualizing the information, that is, the system.
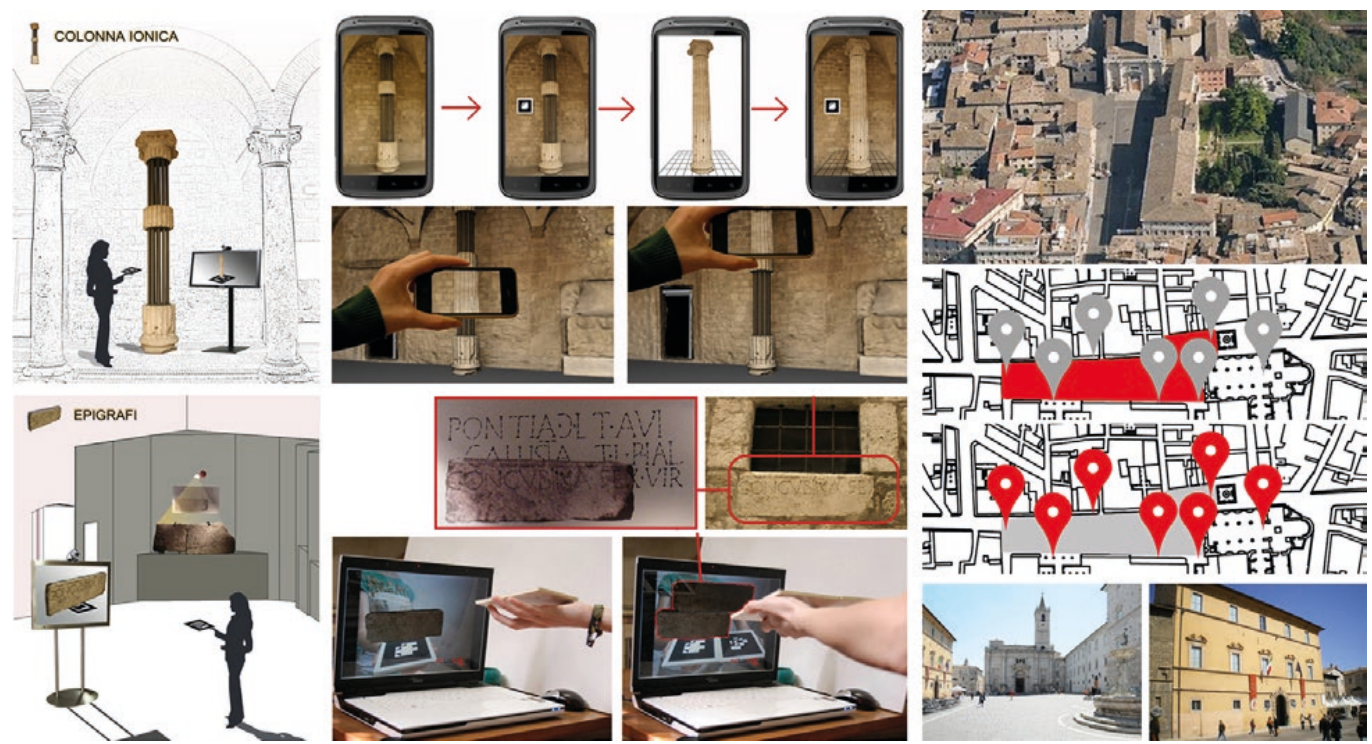

According to this visual, the common thread crossing and linking earlier applications and many more recent ones is very clear: the conviction that representing the inhabited space is still a necessity. This conviction expresses the primary goal of the research, i.e. reinterpreting urban representations, thus taking advantage of all the opportunities offered by visual technologies. It means revisiting the 'representation of the city' because due to the emotional relationship historically tying communities to places, it may still today be a vehicle of emotions for suggesting histories and interpretations, an interface for initiation to knowledge about values and deeper meanings of the city and cultural heritage, and therefore an indispensable tool for its enhancement.

\section{Conclusion}

This revisitation has shown that the role of technological innovation, and AR in particular, has always referred to the goals of the research: collaborating to build knowledge that can be used and enjoyed by a broad public, testing perceptual interfaces that lead to an increase in levels of the subject's interaction with the cultural good. The research therefore features the general goals of identifying 'visual models of knowledge and use' of the goods that are clearly based on rigorous means, but also amplifying the representative sense, using the most useful technologies to do so. 
More in general, different research projects have used AR (recently integrated with the techniques of storytelling, gamification, and storydoing) [4] to transform knowledge about the cultural good into an act of enhancement, and therefore the "visual models of knowledge and use" into an 'experience' not only of the individual object, but of the whole, that is, the system of relationships. This general goal is the starting point for designing paths of historically and culturally consistent meaning to explore "evidence with civic value".

The applications of and motivations for the experiences are all framed within a single horizon that interprets the specific discipline of Disegno in which the role of informational datum is continuously exchanged with the role of the image, which not only represents it, but embodies it in its essence [Cervellini, Ippoliti 2005, p. 75]. By virtue of its spatial/topological connotation, the image renders information by giving it a form at the intersection of three themed objects: the model (iconic), map (also a type of model), and topic (in the enunciative meaning still a model). This common thread - very long, invisible, and indestructible - "can be disentangled without undoing everything" and in which "even the smallest fragment can be recognized" because it pertains to the system [Goethe 201 I, p. 187].

\section{Notes}

[I] For reasons of space, the research referred to in this article cannot be detailed. See, however, the notes, references, and figures. Many researchers have participated in different experiments, including Francesco Cervellini, Alessandra Meschini, Daniele Rossi, Mariateresa Cusanno, Annika Moscati, Jonathan Sileoni, and Danilo Spinozzi at the University of Camerino, and Andrea Casale and Michele Calvano, Cristian Farinella, Lorena Greco and Stefano Volante at the Sapienza University of Rome.

[2] Among these research projects, the primary ones include Maps, technological and spatial models for understanding, promotion and sharing urban heritage, PRIN 2007-2009, coordinator Mario Centofanti, University of Camerino research unit leader Elena Ippoliti; University of Camerino project Towards the construction of a Digital Atlas for the documentation of cloisters and courtyards in Ascoli Piceno, 2006-2008, principal investigator Elena Ippoliti.

[3] The primary research includes Informative integrated Models to know, improve and share urban and environmental heritage. Testing 3D interfaces for 'cultural and geographic objects': the architecture of the information and computerized architecture, PRIN 2009-20 I2, coordinator Mario Centofanti, Sapienza University of Rome research unit leader Elena Ippoliti.

[4] These research projects include the Sapienza University of Rome project Between museums and cities: 'cultural heritage at play' between edutainment and gamification. The role of representation between a technical and humanistic approach, 2020-202 I, principal investigator Elena Ippoliti; Usage/knowledge systems in museum communication, 2018-2019 principal investigator Andrea Casale; Representations of cities and cultural identity. New guides between digital technologies and visual itineraries for the enhancement of the city's cultural heritage and tourism, principal investigator Elena Ippoliti.

\section{References}

Cervellini Francesco, Ippoliti Elena (eds.) (2005). L'impronta digitale. In Spazio Ricerca, III (6).

Goethe Johann Wolfgang von (20II). Le affınità elettive. Milano: Feltrinelli.

Ippoliti Elena, Meschini Alessandra (20l0). Dal "modello 3D" alla "scena 3D". Prospettive e opportunità per la valorizzazione del patrimonio culturale architettonico e urbano. In DISEGNARECON, 3 (6), pp. 77-9I.

Marin Louis (200 I). La mappa della città e il suo ritratto. Proposte di ricerca. In Corrain Lucia (ed.). Della rappresentazione. Roma: Meltemi, pp. 74-94.

Milgram Paul, Kishino Fumio (1994). A taxonomy of mixed reality visual displays. In IEICE Transaction on Information and Systems, 77 (12), pp. $1321-1329$.

Milgram Paul, Takemura Haruo, Utsumi Akira, Kishino Fumio (1995). Augmented reality: A class of displays on the realityvirtuality continuum. In SPIE Vol. 235 I, Telemanipulator and Telepresence Technologies, pp. 282-292.

Settis Salvatore. (2002). Italia S.p.A. L'assalto al patrimonio culturale. Torino: Einaudi.

Author

Elena Ippoliti, Dept. of History, Representation, Restoration of Architecture, Sapienza University of Rome, elena.ippoliti@uniromal .it 
